\title{
NT Behind the Scenes: Breastsleeping the Anthropological Science: A spotlight on Dr, James McKenna
}

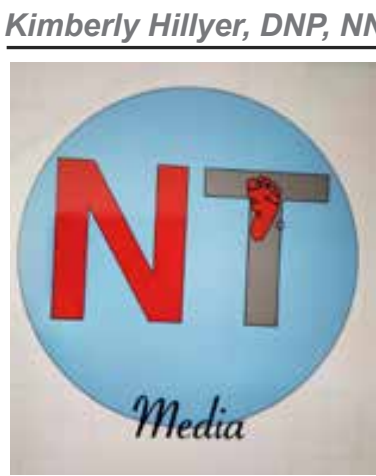

pital, and today we have joining with us, Dr. James McKenna.

Dr. James McKenna is a biological anthropologist who pioneered the first behavioral and electrophysiological studies between mothers and infants sleeping together and apart, and through 30 years of research, Dr. McKenna has become a leading expert looking at multiple topics and issues of sleep development and breastfeeding Dr. McKenna has directed the mother-baby behavioral sleep laboratory at the University of Notre Dame for 22 years and has received numerous accolades. He has published over 130 articles and chapters regarding mothers and babies sleep development, SIDS, and breast sleeping a term that he developed. His work in electrophysiological and behavioral studies with breastfeeding was referenced six times in the American Academy of Pediatrics policies. He is the author of seven books including his new book Safe Infant Sleep: Expert Answers to Your Co-sleeping Questions.

\section{"His work in electrophysiological and behavioral studies with breastfeeding was referenced six times in the American Academy of Pediatrics policies. He is the author of seven books including his new book Safe Infant Sleep: Expert Answers to Your Co-sleeping Questions."}

Dr. Hillyer: Thank you for joining us today, Dr. McKenna. How are you doing?

Dr. McKenna: Great, thanks for having me, Kimberly.

Dr. Hillyer: No problem. I was very excited to be able to speak to you today because this is something as a mother of two that was really interesting to me, especially when it came to your concept of breast sleeping, which I had never heard of. Can you tell me a little bit of how you came up with that term?

Dr. McKenna: You want the true story?

Dr. Hillyer: I do!
Dr. McKenna: All right, you're gonna have it. I think about these issues a lot... what I'm about to tell you probably won't go too, unexpectedly. I was preparing to give a lecture to 2000 , pretty much all women in the Australian Breastfeeding Association. The night before, and like all of us that give talks, you know, as making sure you know last minute before I went to bed looking at all the issues I wanted to address. That night, I had this interesting dream, and someone asked me in the dream... what would I be speaking about and in the dream, I said, "Oh, I'm going to be talking about Breastsleeping," and I immediately heard this voice come out of the back of my brain and said, "Breastsleeping." Yeah, that sounds really good. You gotta wake up and write that down and see what people think tomorrow morning.

\section{"Honestly, it sounds strange, but that's} exactly what happened. I said to them my first slide was "Breastsleeping." I said, what do you think about this as really showing the integrated nature of what we've been trying to explain. How sleeping with your baby is just really not a separable issue to the ways in which babies are fed."

Honestly, it sounds strange, but that's exactly what happened. I said to them my first slide was "Breastsleeping." I said, what do you think about this as really showing the integrated nature of what we've been trying to explain. How sleeping with your baby is just really not a separable issue to the ways in which babies are fed. The idea that obviously, irrefutable fact that breastfeeding wasn't the centerpiece of human development and particularly in the very, very early ages of an infant's life sleep and breastfeeding maternal sleep and breastfeeding infant sleep and breastfeeding hormonal cycles physiology. They're all integrated into a singular system, and I was particularly happy to make that mistake. You know, and rather than saying... Oh, I'm looking at breastfeeding in the context of co-sleeping. I came out in that dream with Breastsleeping, but it really is what is reflected in my research. That these variables that most of us separate out maternal sleep or infant sleep. How many breastfeeding sessions? What constitutes

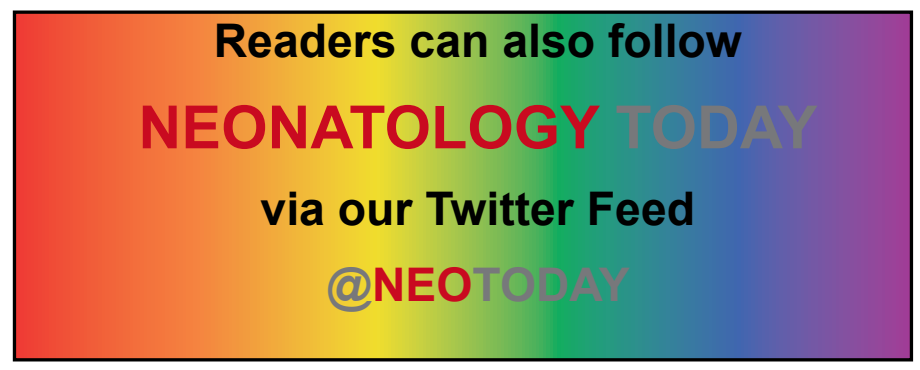


appropriate hormonal responses for mothers and babies and sleep time and all the issues we study? All of them are integrated; each one has relationship to those other variables that we'll be talking about.

Dr. Hillyer: I see, and so you really developed something that really separated out what the medical field has been struggling with when it comes to co-sleeping and how that relates to things like room sharing and bed-sharing, so now you threw in the mix breastsleeping.

Dr. McKenna: Right, I was trying to well, of course, when I really thought about it the next day and I got such a positive reaction. I was thinking about it also in the sense that it doesn't really have any baggage people hear. They go well it's breastsleeping, and I say, "Oh, that's bed-sharing in the context of breastfeeding," which sets up a whole very different dimension of assessing benefits and risks. Because breastfeeding so changes alone without even looking where the baby or the mother is sleeping, it changes the whole physiology of the infant. Obviously, it changes the reproductive cycles and status of the woman as well. So that breastsleeping again as sort of a singular word reflects this integrated...biocultural interdependent functional system, that really is what is the universal pattern of the infant's biological expectations. If one starts with that knowledge rather than trying to think of, well where should a baby sleep or what's normal sleep etc. To first address the issues of who is the infant, who is the human infant from a, strictly speaking, biological point of view. What will come out probably later, as well, as our babies are distinct and that they're neurologically the least mature primate of all with only twenty-five percent of its brain volume. This suggests immediately that immediate parental investment of an extreme nature will be required....and in so far as that's true.

\section{"This intimacy of relatively speaking, almost continuous contact is part of the biology that evolved - The expectations of all the undeveloped immature systems of the human input, not just the brain, but digestion and heart rate sleep cycles and hormonal status. The development of digestion itself, and that's a very hard concept for western scientists who are used to pulling everything apart first to put it all together. "}

This intimacy of relatively speaking, almost continuous contact is part of the biology that evolved -- The expectations of all the undeveloped immature systems of the human input, not just the brain, but digestion and heart rate sleep cycles and hormonal status. The development of digestion itself, and that's a very hard concept for western scientists who are used to pulling everything apart first to put it all together. To say, oh, by the way, you can't understand too much about a baby's eyesight visual range, what it can hear, how it's going to respond without looking at the microenvironment within which the baby evolved. That is the mother, the only environment to which the baby is adapted. Every baby in the world, regardless of culture, you put that baby on the mother's ventrum, and every baby in the world responds in exactly the same way. Increased thermal regulation, breathing is affected, heart rate has affected, blood pressures affected, hormonal status is affected, the actual pattern of breastfeeding is affected. So, you have all together kind of a universal human for a very brief period of time. That's what l've been studying for the first, actually the time period babies are most vulnerable to Sudden Infant Death Syndrome to see whether those clinical variables that are sort of addressed by solitary, usually bottle-feeding babies. How do those critical variables of breathing rates and apnea distributions, how are those issues affected when you put the babies in the environment within which the baby's sleep and architecture and breathing? All of those clinically important factors evolve, therein you get and derive what truly does amount to human infant normal sleep.

"How do those critical variables of breathing rates and apnea distributions, how are those issues affected when you put the babies in the environment within which the baby's sleep and architecture and breathing? All of those clinically important factors evolve, therein you get and derive what truly does amount to human infant normal sleep."

Dr. Hillyer: It's interesting that you saw all that because, for the most part, neonatology has been looking at the thermal regulation of infants and how that has helped with growth in terms of them being in the Neonatal Intensive Care. So, it amazes me that we haven't yet put that together and especially in the policy for the American Academy of Pediatrics.

Dr. McKenna: There are some complex issues here, so of course, to a certain extent and depending on how premature infant is we're really working in, if I may unchartered territories in the sense that the baby is being born in a context, now that it is possible for that baby through artificial interventions to live. So, what I mean by unchartered territories is never before during the evolution of human infancy. If a baby was born at 24 weeks or 28 weeks, would there ever have a chance of the baby living? So, to a certain extent, I understand why sometimes we are tending to sort of distance those premature babies from somewhat could be thought of as really being relevant under normal gestational ages -- Things that are really important to the neonate, an infant that's had a full term. That said, what's interesting coming out of neonatology has been some of the greatest representations of the importance of looking at babies as reflecting a contiguous life with what it was sensitive to within the womb. In fact, some of my colleagues have suggested [to] Julie Rutherford, one of them that actually the breast becomes the new umbilical cord. Indeed, that's a really important point because it brings the baby to the mother. You're always guaranteed if the baby is breastfeeding, that mom's 
going to be very close, and indeed that permits and sets up a continuation of the regulatory mechanisms that were intrinsic to the intra-utero baby. In fact, Ashley Montague many years ago captured that concept by calling human infants extero-gestates, meaning they finish their gestation after the womb compared with other mammals. Indeed, it's true we are the only primate that can't cling, for example, to the mother's ventrum because the motor neurons are not developed.

Thus, infant carrying behavior turned out to be an extremely important selective pressure on evolving human mothers. Really, it's fascinating. I obviously wouldn't have time to go into all the human adaptations that are actually explained by the vulnerability and the prolonged vulnerability of the human infant, how societies and adults and everyone in the groups had to adjust and did behaviors to make it possible for such energetically expensive little creatures to survive. So, we evolved empathy. You could fall in love with anybody's baby and be willing to help them. You do, and we do, so it had bipedalism. Actually, if you want to take it one step back, upright posture changed the architecture of the woman's pelvis because it was so utterly beneficial, freeing the hands to do other things to make tools manipulate the environment alongside the emergent large, relatively large brain. It really permitted or necessitated a group response in the emergence of empathy of caring. So much about what others think and having a theory of mind where we know what people are likely thinking given those circumstances. We care about it, and that's unusual. We think that the origin of empathy, the ability to give your life for the sake of a perfect stranger in many ways, is the result of our need to bond with not just babies and those who are biologically related, but with others in our group in very significant ways. That care of infants, although that's true for many mammal species this collective generalized response to babies, but in the evolution of human emotional structures literally the capacity to treat other human beings that are non-related to you as being related is, in fact, a central part of our adaptation. It's generosity and giving up for the sake of the other it extends out, but it was originally because we were giving birth to these little babies that the only way they could be born safely given that the brain size was going to get so large was to roll back the immaturity of the brain relative to how large it would become. As an adult, so babies are born ever increasingly in our evolution earlier and earlier in terms of its ultimate neurological maturity birth.

\section{"We care about it, and that's unusual. We think that the origin of empathy, the ability to give your life for the sake of a perfect stranger in many ways, is the result of our need to bond with not just babies and those who are biologically related, but with others in our group in very significant ways. "}

Dr. Hillyer: And with this group empathy that you were talking about, how does that relate to other family members, whether it's fathers or grandparents participating in the engagement of sleep with infants?

Dr. McKenna: You probably, well maybe you know that generally speaking that most cultures in the world as individuals in it never sleep alone in general. Obviously, part of that is that most people around the world do not have the choice of multiple bedrooms, so on and so forth, even where there are possibilities of other beds. Many cultures, in fact, never let babies sleep alone, and when they get larger, other babies come along; grandmas and grandpas are really important in the sense of caregiving patterns and always have been throughout our evolution. When there's an effect in anthropology, there's the grandmother hypothesis and why women and men live so long post-menopausally for women. After reproductive age, it's to contribute to their relatives and friends' babies to help take care of them.

Dr. Hillyer: That's very interesting, I never have put those two things together. Very, very neat aspect, and you said that you had seen this happen with your anthropological studies in different cultures.

\section{"Many cultures, in fact, never let babies sleep alone, and when they get larger, other babies come along; grandmas and grandpas are really important in the sense of caregiving patterns and always have been throughout our evolution. When there's an effect in anthropology, there's the grandmother"}

Dr. McKenna: Yes. I can tell you as a kind of a biological anthropologist, but also trained in the other subfields, cultural anthropology, linguistic anthropology, archaeology. You all have to, as an anthropologist, develop knowledge and skills to relate your particular subspecialty. Like mine is human evolutionary processes in relationship to our contemporary species... Most cultures around the world, they hear that there's any part of the world, but they put their babies somewhere that they are not think [ing]; this is a form of child abuse and neglect. In our parlance of today's and kind of unthinkable because of the biology, that's what's so interesting. Culture can change any way it wants practically with social values and ever-increasing ideologies and thinking this is the right thing to do. The genes, in this case, particularly the genes of the infant, have remained constant through time pretty much constant through time in terms of this neurological maturity what that requires to buffer them in terms of the external world. It's done through complete and utter social interdependence and the complete dependence on the baby through a very long period of the child's life. You know, for the first third of a child's life, a human being's life, they are in some way or another dependent on caregivers for their survival and well-being; it's very unusual.

Dr. Hillyer: Do you think that that's maybe one of the reasons that the Academy of Pediatrics then opened up their policy -- to say that room-sharing was something that was definitely appropriate 
for infants up to the first year of life?

Dr. McKenna: Right, oh of course, and all our studies originally, but now other people have joined in, it's just undeniable. What kinds of physiological changes are happening to babies when they're sleeping in the context for which they were designed. Lighter sleep, not deep sleep, which gives babies benefits of terminating apneas for the appropriate form of sleep, deep sleep. You don't want babies sleeping too long, too hard, too soon, and that's what solitary sleep and particularly bottle-feeding solitary sleep promotes. For the babies, about ten percent of which are more neurologically even less mature with some deficiency, you don't want to push them into an environment for which the most difficult form of sleep to terminate apneas is characteristic. That is the form of sleep that puts them alone, and of course, you complicate that even further by putting them on their bellies. That even promotes deeper sleep and gets some babies in trouble, in terms of turning face down, and their muscles aren't strong enough to turn away from. What's interesting too, isn't I didn't say anything about dads in this picture thus far, but what we've recently found out, particularly through the work of Dr. Lee Getler at Notre Dame, who's been focusing as much on the changes in male reproductive physiology and reproductive stages. As for the most part, historically, we've concentrated on women's reproductive stages through time, and what he's been able to document is, in fact, physiology that changes with his reproductive status. Birth mating patterns, where testosterone is high and oxytocin is low.

\section{"As for the most part, historically, we've concentrated on women's reproductive stages through time, and what he's been able to document is, in fact, physiology that changes with his reproductive status. Birth mating patterns, where testosterone is high and oxytocin is low."}

Partnering with a woman in whatever form that takes. Where testosterone goes down significantly when men have their first child, that testosterone, which is sort of associated with risk-taking and competition, etc., risk-taking goes down. When that " $T$ " goes down, and oxytocin goes up. When they have, like I mentioned, their first child, then this is so fascinating too, which we've been able to document. Also, by using data from our sleep lab where dads were there too. The longer the dad spends in physical contact with his baby, his testosterone adjusts to that, too, and also goes down significantly while prolactin and oxytocin go up. Now you might think that, of course, men think that's not good. You know, testosterone is always associated with western concepts of masculinity...having big muscles, and obviously, it plays a role in that behavior or that physiology for men, but what it always does, it puts men and their moods in more stable and nurturing kinds of context. If manliness rather than thinking about big muscles is associated with how successful his children are, how long they survive, and whether they survive then. Then being masculine would, in fact, not relate to how strong you are or how you meet western cultural motifs of the beautiful man, but how that man is able to care for his infant emotionally and invest in that baby because it's all about that, that's important for these energetically unbelievably expensive babies actually whose energy requirements exceed any one individual's ability to provide it, that's the key.

We know that now that babies are born not just because of the obstetrical dilemma, where those babies have to get out before their brain or head cranium gets too large to prevent the baby from successfully passing through the birth canal. We also now realize in recent research that what's happening is the trigger for birth occurs also when the mother's ability to provide the trajectory of brain growth that she has already provided is exceeded. When that energy level then stops the growth of the brain, then it's time for the baby to be born such that the external contact and breast milk continue as an incredibly critical part of it, but so does the enrichment of that social external environment to the baby. That's going to affect inter-neuronal growth, interconnections between the brain, and that ability to continue the trajectory of growth that was occurring in the uterus, but which at some point, the need for you know what is it twenty-five percent of the energy that's put into the brain on a daily basis; that huge amount of energy no longer can be provided to the baby by the mother's body. So, I am just pointing out that fathers are really important, and they too have a hormonal paternal evolutionary history that explains, yet again, what we know babies actually need, which was never asked when in the 30s and 40s or even at the turn of the century. You know, I hate to say it, and not to pick on any one race group in particular, but when white MDs, who probably never changed a diaper, by the way, started assessing how best babies should be cared for. None of those individuals had ever studied babies. There were no observational studies, no empirical physiological studies looking at the human infant. Who are they, how does the biology work, what are their brain growth patterns relative to other species, and this comparative basis not just with other animal species? Reallife history but also comparisons with what people do with babies around the world. And sure enough, when you look, they're all they would never dream of not sleeping with their babies. So that has to count for telling part of the story, too. In addition, to the studies that we have conducted that really look at the role that the physiological regulatory effect of contact plays in changing almost every variable with respect to the physiological experiences.

\section{"There were no olbservational studies, no empirical physiological studies looking at the human infant. Who are they, how does the biology work, what are their brain growth patterns relative to other species, and this comparative basis not just with other animal species?"}

Dr. Hillyer: Now, I feel like Neonatal Intensive Care Units around the nation has started to really take heed to what you're saying and really implement and encourage skin-to-skin contact right away with both the mother and fathers and even other support 
people. Is there anything else that you could see us doing in order to bridge this concept a little bit more for home?

\section{"Let me start with what we have a lot of data on. Which is starting with the premise that every human infant, regardless of culture, their body is designed to work in relationship to sensory exchanges with the caregiver. Every culture, and as I mentioned, I think earlier you put any baby from any culture on its mother's ventrum. Its heart rate changes, its blood pressure changes, its cortisol levels change, its breathing patterns, its distribution of apnea has changed, its growth rate changes."}

Dr. McKenna: Let me start with what we have a lot of data on. Which is starting with the premise that every human infant, regardless of culture, their body is designed to work in relationship to sensory exchanges with the caregiver. Every culture, and as I mentioned, I think earlier you put any baby from any culture on its mother's ventrum. Its heart rate changes, its blood pressure changes, its cortisol levels change, its breathing patterns, its distribution of apnea has changed, its growth rate changes. Tiffany Field showed years ago that you give a massage and a baby a lot of contact physical contact, and it puts on she found 47 percent more daily weight gain every day. No one could believe it until they went out and did studies, and sure enough, boy, you give babies more contact, and whoever they are, they grow faster and more, more assuredly. So we know that, and we've known for many years, it came out of neonatology. Dr. Martinez and Reyes, if you wouldn't probably remember, because you're too young, I suspect, in the 70s, they were the first to send these little premature babies parked in the chests of their mothers because they had no more room for them in their hospitals. I believe it was Quito Ecuador, I believe I could be wrong on that, but they thought these four little prematures were not going to live. It turned out that putting these babies parked in their mother's ventrums between their breasts -- those babies had a higher survival rate than the babies that were staying in the incubators in the hospitals, and it was them that wrote this paper up and introduced this whole notion of either skin-to-skin care, kangaroo care as it came to be called. Now in the contemporary context, just a couple of years ago,

Bounty with a group of colleagues did a meta-analysis, meaning she collected as many studies of the outcomes of premature babies and the care that they received in the hospital; to see what their survival rates were, the percentages of babies returning to the hospital, sepsis, hypoglycemia, oxygen saturation levels, and all that. What has been improved hundreds, thousands of times over is that now, not only are these babies growing faster. They have less stress, less cortisol, but their survival rates, at least according to Bounty's average from all the studies, which is 37 percent less infant mortality rate of premature babies that have received skin-to-skin contact or kangaroo care as it's been called. That is, the important thing also in terms of adding to that is it's not a female body thing necessarily; it is a body thing for the infants. The dads can do this kangaroo care and get the baby's heart rate more stable, blood pressure down, less crying, a more light stable sleep with less apneas. So, the baby is again it's mimicking as much as possible that uterine environment. So originally, I just wanted to give credit to these Pediatricians specializing in neonatology that they might have learned it inadvertently, but they were the ones that made it well known around the world. The Karolinska Institute in Sweden and many centers of real infancy, neonatal, and premature studies emerged have now hundreds of studies documenting how critical this is even during that premature period. Now it's true that prematurity does make depending on the age and degree, and as opposed to the gestational age of specifically each baby too, but babies are more fragile. They don't have the capacity to engage in reflexive activities that a full-term neonate does to suffocation or a potential for suffocation. Believe me, there's only been one study that I know of on normal newborn infants to look at their reactions to having their nasal passages blocked in one form or another.

I always hesitate to tell this because it sounds like such a terrible study to do, that would never be institutionally approved...but that said, it wouldn't be, but they took newborns, and they put cellophane over the newborn space, and that was one of the things, and then the researchers put cotton up the baby's noses. The reaction of these newborns that aren't supposed to be able to do this was dramatic. In one case, it took two individual nurses to keep the baby stable from its head backing, it's arching, it's batting at the stimulus...the description is remarkable.

You definitely get the picture that for that normal little baby, that baby is not just a little protoplasmic blob waiting to have its nose or its mouth suffocated...they were like fighters.

Now that's your normal healthy baby, and premature babies, of course, would not be able to give that kind of really reflective genetic-based response to this you, know blockage. That said, the baby still, as his in evidence, they need the contact, they need the contact, but for some babies, it probably is not wise to put them, depending yet again on the age and maybe the physicians or Neonatologist's assessment of the relative strength of this baby. It's not an easy thing to say that they should be close sleeping or bed-sharing with their caregiver because they are more fragile. So that's that is a problematic for the issue of breastsleeping, etc., but of course as, as I know that the field is doing ever-increasingly they're really attempting not to make assumptions about what these prematures can do or not do, insofar as particularly getting in some form or another, breast milk, which of course would be absolutely ideal even for premature infants. So, neonatology per se opened our eyes; if now, if we could only appreciate what does this actually mean still from the newborn, these babies are contact seekers. They are designed to; they're designed to live and to feel things, not cognitively evaluation and judging, so they're not making any judges, they're not culturally socialized yet. They are as close to their genes as they'll ever get, and the genes are finding the most direct expression in whatever environment they're going to be found in.

If we really look at the responses babies give to whatever caregiv- 
ing practices we administer to them, we get a very, very good clue as to what's in their best interests. Babies aren't plotting and planning and making agendas. They don't have any wants, they don't want anything, but they need things, and the need is very honest, fundamental, and biological. I can guarantee you that there isn't even an infant, not to mention preemies, which are different categories. There isn't an infant, that if they could talk, would say, "oh yes, I really think this idea of separation at four months, just yeah, it's really cool, you know, yeah put me in there I want my own bed." I think it's one of the crimes we commit about babies is inadvertent; however, so we tend to assume from a cultural, social basis, oh yeah, that should be good for babies. Teach them a little independence for five months, the little rascals, you know, I heard this put like that in a newspaper article. The little rascals, those little four-month-olds, they know what they're doing, and I could have screamed, you know. Those babies don't have an agenda. They are giving you an honest assessment of what's in their best interest.

\section{"That's why I am, I dare say, I am absolutely opposed to any kind of sleep training. I feel it's an absolute form of cruelty. I know parents don't mean it in that way, but let's face it if an objective alien came down and looked at what this puts babies through. It is unfortunate that oftentimes it's portrayed as an important developmental landmark to self-soothe."}

That's why I am, I dare say, I am absolutely opposed to any kind of sleep training. I feel it's an absolute form of cruelty. I know parents don't mean it in that way, but let's face it if an objective alien came down and looked at what this puts babies through. It is unfortunate that oftentimes it's portrayed as an important developmental landmark to self-soothe. That's a complete social construction, and so is the alleged need for early sleep consolidation. I can assure you that babies do not benefit from anything other than what their own body metabolism, body shape, their weight, their growth patterns is normal and good for them. Babies all over the world will selfsoothe in their own time and place. Tom Anders who came up with the observation that if you look at babies in the video, by video cameras, crib sleeping baby, solitary sleeping baby. He named two types. They were the signalers, that the minute they woke up looking around, "Hey, where is everybody," you know, "Hey, this isn't, I don't feel right." Then there were the self-soothers that would look around for a while and go back to sleep. Now what's happened is we've come to think of the "good baby syndrome." "Oh, is your baby sleeping through the night?" You know it's one of the second questions asked, after, "what is your baby sex?" "Is your baby sleeping through the night?" As if this is good for the babies. It's not good for the babies, especially sleeping through the night and alone. That's in a completely social-cultural category of its own, this whole constructed concept of self-soothing, which Tom Anders never intended to be a developmental step or some- thing that the good babies do. Then there's all the rest of those, you know, kind of bad babies. You don't want to mention it. No, it's a culturally constructed phenomenon. I hear these things being said by these pop-up sleep clinics that are fueling this run... Your baby's going to miss out on some important social skills unless they get this; that's just not true. I just want to make that sure to make sure people really know that. Now what parents might feel they need to do within bounds or so, but ideally, there's no need to do it, etc. So anyway, I got a little bit off the track, but what would you like to ask?

\section{"Hearing the work that you do makes me then wonder, how can medicine take a step back in understanding multiple different cultures -- not just looking at just western cultures reactions, but looking at multiple different cultures in order to incorporate a better policy moving forward."}

Dr. Hillyer: No, no, no, this is great. You know being, able to understand how cultures and different cultures work and how it has influenced the way medicine has made policies is extremely important. Hearing the work that you do makes me then wonder, how can medicine take a step back in understanding multiple different cultures -- not just looking at just western cultures reactions, but looking at multiple different cultures in order to incorporate a better policy moving forward.

Dr. McKenna: So, I don't chide our culture for thing; we do pretty darn good here, we're a good group, we're a good culture. In this sense, I believe we have gone over and overstep boundaries and thinking that this whole western innovation supposedly a baby sleeping alone and how great it is for them it never was substantiated on any empirical grounds whatsoever. Here is where we could have early on very much benefit before jumping to making universal claims about how great it is, in the baby's best interest to be separate. How great it is for the parents and that lady's life will be good, and the baby will be great. To jump to the conclusion that not only is it the best thing to do, but it's too bad those other cultures don't get on board. We need to import this "pseudo-scientific," and it is "pseudo-science" because it isn't that scientifically based and factual that babies benefit by being separated from their caregivers. No, that's never going to be shown or proven because it isn't true. Originally, it isn't even necessarily Kim that you get validation for these things. From looking at which is important where do babies sleep around the world, hands down, they are all in whatever diverse form it takes, and there is many diverse forms as there are people cultures doing it. But nonetheless, the important ingredient is access to the sensory signals that mothers and babies would give or the caregiver the ability to respond to the sensory signals. The heat, the sounds, the smells, the movement, etc. That is, it's critical, but I came to this from watching monkeys originally and studying the parenting ecology; what is it that determines forms of contact prolonged restrictive permissive in non-human primate societies. I studied the North Indian 
language, so I was very familiar with the way environmental factors shape the specific ways babies are cared for. Now when you think about primates, you can get a huge idea about where babies belong by simply realizing that there isn't a non-human primate around that doesn't spend prolonged periods in unbroken physical contact with its mother's body. Chimpanzees which are the higher primate, gorillas, and orangutan, take the higher apes; all of them really prolonged associations between the infants. Then the children of those parents and it isn't just a nice social idea here. It's developmentally based. What are those children capable of? What are those babies capable of? The chimpanzee infant doesn't even break contact at all with its mothers for about four to five months.

We have a baby born that neurologically speaking is about twenty to twenty-five percent less neurologically developed than a chimpanzee, which can cling to its mother's center right away, so I was familiar though I didn't do those studies myself in the '80s. All of a sudden, we got away from Harry Harlow's work. Do you remember the two kinds of monkeys? The surrogate ... that had the bottle available to it and had a steel rim mother with a bottle sticking through, and the other place was no bottle, but a terry cloth soft fake mother wrapped around. The monkeys all preferred not the bottle, and the milk. [They] preferred the secure soft, warm cozy terry cloth mother. It was a huge breakthrough because it was extremely consistent previous to that Freud had argued that one of the drive theories is the satiation of the baby's stomach and that attachment came along with the baby feeling, "oh, that's so nice." Even at the monkey level, it was determined by Harry Harlow's studies in the ' 50 s and would never replicate them because they were pretty cruel to the monkey baby, but he showed that even there that it's something else that monkeys need. They need that social support, that feeling of emotional protection by contact rather than being the factor that brings babies to fall in love with and attach with their mothers, so we were alerted to that. Then in the ' 80 s and early ' 90 s, all the monkeys and apes were studied in laboratories. Most of them not there were field studies, too, don't get me wrong, but in the lab to find out what was underlying the contact if you separate a monkey or a baby right at birth what physiologically happens to the ape.

\section{"Much more hydrocortisol production, heart rate changes, fluid in the lungs developed in many of the monkeys. They lost their appetites. Their sleep was all interrupted. They had oxygenation drops. In other words, even at the level of monkeys' three-hour separations, three- day separations didn't just reflect a social loss. It reflected underlying physiology. "}

With a monkey, even if you're trying to keep it and yourself as a human caregiver, what happens to the baby? How about three months? At three months, you take it away from this mother. What about six months? Well, all these studies done on at least 30 - 35 different primate species showed immediate physiological consequences to hormonal levels. Much more hydrocortisol production, heart rate changes, fluid in the lungs developed in many of the monkeys. They lost their appetites. Their sleep was all interrupted. They had oxygenation drops. In other words, even at the level of monkeys' three-hour separations, three-day separations didn't just reflect a social loss. It reflected underlying physiology. That's what was dependent on that social relationship for undeveloped primates as they are not even yet to get to the human the social and the physical can't be separated; they're one and the same. In other words, there's a physiological regulatory effect that comes with this nice social idea, and it's not a nice social idea alone. As Harlow showed kind of dramatically, that the monkeys that had their mothers taken away were never normal, ever again. They needed to be looked at, be taken care of. So even the monkeys that were on the terry cloth, monkeys that only stooped over to get a little milk when they were starving...only did so for about twenty minutes or a half an hour during the day. That was possible for them to do it they wanted to stay on their terry cloth emotionally soft caregiver. So, I'm just trying to make the point that already in the ' $90 \mathrm{~s}$, when I started realizing there could be a possibility between this western unique, western tragedy of babies to healthy baby suddenly dying in the night and crib, that there could be a connection with this dismantling of what was an incredibly intact important biocultural system. We took away breast milk and breastfeeding, which made possible the ability to supplement bottles and thus to put babies somewhere else. Which we did, we separated them, put them in little rooms, and finally even to promote deeper sleep; yet more, we put babies on their tummies because they arouse less frequently. They sleep longer, and they sleep longer in a deeper stage of sleep. So, three major components each of what we dismantled from cultural information and values, each of those is a risk factor independently for Sudden Infant Death Syndrome; not breastfeeding putting babies prone for sleep, and putting babies in cribs by themselves. Now you mentioned room sharing, I get perturbed by this concept. I'm very happy; finally, the American Academy of Pediatrics recommended and actually knows now that babies need to be in proximity to their caregivers, but what I don't like is this kind of euphemism you might call, calling it room sharing. It is not the inert walls of the room that are being shared with, that babies that's keeping them alive. It's what's going on in that room between the mother and the father and that baby. I can guarantee that it's the vigilance, it's the checking, it's the touching, it's the responding to noises or lack therein of noises of the baby.

A baby that sleeps in a room by itself has a fifty percent greater chance of dying. Imagine that fifty percent, really, a chance alone before you go anywhere on that issue. Yet what is so terrible for my 35 years or so of studying this is that we're caught in this terrible situation. You know, like when cartoon characters run off a cliff and their feet are running around, they don't know that there's nothing underneath them. Then finally, they fall. Well, I think that's what this can be used to describe, where we are at. The animals or the cartoon characters spinning is this notion that sleeping with your baby or bed-sharing is a pathology. It's not a pathology; it's an adaptation. What they're confusing it with is how the practice is practiced, which is very different. Let me give you an example of what I mean by that, the baby sleeping in a crib face down or prone who dies through the night, the diagnosis would be SIDS it would be considered. The solution would be to teach safe crib when your babies are on their backs, take out the fluffy material. 
Now we know to bring that crib in and put it next to the bed. So, let's think about the baby dying prone in a bed-sharing environment, where the double standard exists. So even if the mother says, "I really wasn't near the baby," the baby died, the cause of the death would be said to be bed-sharing. The solution would be to eradicate bed-sharing; in other words, the baby was sleeping prone, which is singularly one of the highest SIDS rates there is. Yet what has happened in this discourse on that sharing, and it isn't discourse, that's the problem. It should have always been an actual conversation about the clinical characteristics of each parent's situation. What they think, what they know, what they feel, and that's what l've been arguing for years. Not that everyone needs to jump in bed with their babies, no, but never argue that I don't actually even advocate this out, but kind of application of bed-sharing for all. No, l'm advocating for informed choice. Using actual, well-rounded scientific information, and that is what I am disappointed that the American Academy of Pediatrics refuses to consider and change.

\section{"Not that everyone needs to jump in bed with their babies, no, but never argue that I don't actually even advocate this out, but kind of application of bed-sharing for all. No, l'm advocating for informed choice. Using actual, well-rounded scientific information, and that is what I am disappointed that the American Academy of Pediatrics refuses to consider and change."}

What's happening is its kind of like an underground up, bottom-up revolution. We get anywhere from one and a half to two million mothers right now while sleeping with their babies and breastsleeping, breastfeeding their babies. Once that breastfeeding genie was out of the bottle, that changed everything in terms of where babies were going to end up because of the way the system works. I mean, it just doesn't make sense; some others do in part because they're worried they might suffocate their baby. The very ones that probably would never suffocate their babies, but nonetheless, they put them in another room. It's pretty inconvenient to get out of bed and to go get your baby, and you've already upset the baby; they're already crying to signal you, which makes it harder to resettle the baby. So, in our studies, we've looked at mothers and babies sleeping in the same bed, sleeping apart. Over three nights, we looked at both mother and baby physiologically. Full physiological montage, oxygen, heart rates, body temperatures, sleep architecture brain waves from the mother and the baby. We had routine bed-sharers who, one night of the three, would do the opposite sleep apart. We measured them both apart; as we did, we took routine solitary sleepers, but with one commonality with the bed-sharers, they were exclusively breastfeeding. So, all our mothers were breastfeeding but just putting their babies somewhere else. The routine solitary sleeping moms would, the first night, do what they did at home, sleep separately in different rooms. Keep in mind we're monitoring their brain waves, body temperatures, heart rates, and everything. We got a good pattern of what the babies looked like, they were very different than the breastfeeding baby sleeping in bed, but l'll get to that in a minute. Then for those solitary sleeping couples the next night, we drew to see if they'd do an experiment which for them would be to sleep in the same bed or they did the same thing they did the night before, which was to sleep in their normal home situation which was in separate rooms and the third night we did the opposite of whatever they did the second night which was for the routine solitary sleepers the dead chair oh no l'm sorry for the third night gave two nights randomly to the normal night and the third night would be the opposite of what the group would normally do. We got what's called a between and within-group design, which is the best kind of cross-sectional physiological study you can do. We found that when exclusively breastfeeding all our babies were, keep that in mind when those babies were in the bed that sharing environment, they all moved physiologically and behaviorally in exactly the same way. When the baby separated the routine, bedsharing babies didn't sleep with their mothers, they never went down very far in their numbers of arousals and things like that, but their patterns of all these clinical variables began to match that of the routinely solitary sleeping breastfeeding babies...In other words, bed-sharing acutely changes what happens to the baby right away. Solitary sleeping exactly; it changes quite acutely what happens in the bed. Now always our are breastfeeding babies whether they were sleeping alone in a room next door or in the bed. They always breastfed more, significantly more, but not as much more when they were in bed. Our solid usually solitary sleeping breastfeeding babies when they were in bed, all their numbers went way up, the number of breastfeeds per session. So, we knew that those were real, real important kinds of mechanisms of change that are defined by where the baby is sleeping.

\section{"They always breastfed more, significantly more, but not as much more when they were in bed. Our solid usually solitary sleeping breastfeeding babies when they were in bed, all their numbers went way up, the number of breastfeeds per session. So, we knew that those were real, real important kinds of mechanisms of change that are defined by where the baby is sleeping."}

Dr. Hillyer: So, I think that one of the things that was really solidified after the initial "Back to Sleep" campaign that the AAP and other agencies put in place is that they did see a dramatic decline with SIDS and then it sort of settled in. Now with the fact that we are trying to implement and have more breast milk use, breastfeeding, and in addition, with the idea of the room-sharing. Do you think that breastsleeping is going to be at odds anymore with the future of sleep guidelines? Because to me, it sounds like although behind in the times as far as the policy. It is starting to catch up with what you're actually seeing and studying? 
Dr. McKenna: Yeah, it's ecology itself actually playing out, honestly. That's the power of, dare I say -- these are all scientists I'll be speaking to here; it's evolutionary-based. I didn't begin my research on sociocultural ideas about babies; they were from this cross-cultural, this cross-species. The separation studies of monkeys and apes that really gave me, in this case, the clue that wow, I think we need to really look at what would be from a species-wide perspective of normal sleep. So, what I'm just trying to point out is that, yes, I believe and I'm very hopeful that this term breastsleeping without a lot of baggage associated it, is defined by the absence of all known hazardous factors that could be associated with bed-sharing. You know the baby always on its back, of course, you know a stiff mattress, is centered, nobody in the bed desensitized by drugs or alcohol, no maternal smoking. That any baby experience this is huge. In fact, I always say that, and I'm really disappointed that the AAP hasn't put above everything else a smokeless gestation as being the very first way you can have safe infant sleep. Smokeless gestation, secondly breastfeeding, and thirdly avoiding the prone sleep. Altogether avoiding other children in the bed, having removed all the spaces between headboards and mattresses, or pushing the mattress against the wall. Not knowing parents that it's migrating away and the babies caught in that space or at an end table where there's a space between the bed. That what's interesting is some of those dangers actually go away in the bed-sharing environment because the baby is so absolutely focused on the mother they just don't move around.

\section{"One of the ways in which the solitary} bed-sharing baby gets into trouble is either the mothers place the babies on the pillow, which is a kind of a dangerous sleep environment, but also the babies move around in the bed more. Whereas the breastsleeping baby is just fixated, literally under the mother's arm looking right at chest level with the mother's body and doesn't want to go anywhere else. "

One of the ways in which the solitary bed-sharing baby gets into trouble is either the mothers place the babies on the pillow, which is a kind of a dangerous sleep environment, but also the babies move around in the bed more. Whereas the breastsleeping baby is just fixated, literally under the mother's arm looking right at chest level with the mother's body and doesn't want to go any- where else. Not only that, but universally no mothers had to be told to put their babies on their backs because they're all breastfeeding, and the only way you can get a baby to breastfeed is to let it move to the breast and away from the breast on the back. You can't feed a baby very well, sleeping prone, and let it trying to get to the breast. So, yes, I think, and I'm very hopeful that we move from this monolithic, and it's really an unbelievably long beginning point of thinking no matter what one that mothers can't protect their babies when they are informed. That's one of the difficult factors that I think is holding up the AAP from agreeing that mothers can responsibly sleep with their babies even in an urban cultural environment where there are such things as mattresses and headboards and those kinds of things. But, I think that we're getting there, but I still hear the two major people; I won't mention names on the committee, still saying without any qualifications, "bed-sharing is dangerous, bed-sharing is dangerous, bed-sharing is dangerous." It was interesting before we got to those recommendations in 2005 that was when the actual recommendation was never the bed-sharing. It was interesting.

\section{"They had a description of all the safety factors for the solitary sleeping baby and the same things they were saying about bed- sharing, you could exactly say about solitary crib sleeping."}

They had a description of all the safety factors for the solitary sleeping baby and the same things they were saying about bedsharing, you could exactly say about solitary crib sleeping. I didn't ever point it out to them, but every single one of the factors of what happens with bed-sharing was saying risk factors when babies were except for the overlaying of the mother, but it was a nonconscious cultural ideology that they didn't realize. If you begin with the premise, a priori, that no matter what it is, whatever form it takes, bed-sharing is dangerous, you're never going to get to the point where you're really trying to, you're starting off at the wrong point. It's not that it's inherently dangerous; it can't be because that's how babies have lived, but it can be made inherently dangerous, and that's a huge difference. That is what they have been very disappointingly, not able to actually begin with listen this is a proven time-honored cross-species valid and intra-species valid, important beginning point for babies affecting neural biological growth and development. Affecting the development of the immune system, itself I mean, now that deals with breastfeeding too, but breastsleeping does include. It's defined by breastfeeding in the context of a hazardous bed-sharing environment, but again I think that the mothers and babies are defining what they're doing. Now we have to bridge what the small 9 to 12, the 15 person com-

NEONATOLOGY TODAY is interested in publishing manuscripts from Neonatologists, Fellows, NNPs and those involved in caring for neonates on case studies, research results, hospital news, meeting announcements, and other pertinent topics.

Please submit your manuscript to: LomaLindaPublishingCompany@gmail.com 
mittee, now keep in mind; most people don't know this; millions of mothers around the world millions and millions are being affected by what a very small insular handpicked group is thinking. No discipline differences, people that represent really different lines of evidence like anthropologists. I have to keep saying it because psychologists now are actually looking at these issues from this perspective. So, it's changing...I could tell you names, but a very big group now is beginning to understand these beginning points as having been erroneous.

\section{"The problem for me has been in my career is that I'm fighting two paradigms at the same time, the SIDS research paradigm and the pediatric sleep paradigm, and both are suffering from false beginning points that cultural assumptions have been used as the basis of making recommendations."}

The problem for me has been in my career is that I'm fighting two paradigms at the same time, the SIDS research paradigm and the pediatric sleep paradigm, and both are suffering from false beginning points that cultural assumptions have been used as the basis of making recommendations. A big epidemiological studies for SIDS that...asked more carefully the important questions about bed-sharing. I'm convinced now that I've seen other studies that show how parents with such negative rhetoric about bad sharing are not telling pediatricians that they really do sleep with their babies. It's a complex question that to answer actually, Kim, because suppose you have a crib and you put your baby in your crib in the beginning of the night, and some researcher that you have a feeling wants you not to be bed-sharing you say, "oh yes, my baby sleeps in the crib," but what they're not saying is the baby is relocated. You know, at first feed and goes into the bed, which is a very normative pattern and unless you want to believe that in the middle of the night, the baby started levitating out of the crib and floated down the hall and dropped into the parents' bed, which I doubt. So, it's a hard question to answer, but a lot of parents don't even know that they really do bed-share. I mean, in a sense, they know where the baby's supposed to be, and they think it's just kind of a little exception. You know what I mean, so it's fudged, and that data sometimes is very close as to whether or not the bed-sharing and the epidemiological study proves to be a factor. Now smoking in bed-sharing is 20 - 30 times greater risk. So, you really see how individual risk factors can play out obviously in the safety of bedsharing. That's why it's not an easy concept to really work with, but we see that the breastfeeding and the breast milk through multiple studies now are changing everything. If it can't go on that, the American Academy of Pediatrics is continuing it is going to be considered a fraudulent form of science. That people know now there are very different ways to be looking at this issue. Important legitimate scientists in legitimate science is being presented in all the best journals. It's all there, and it has to be considered, and I'm hopeful in the next set of recommendations that the committee changes that the people that have these other perspectives. It's not meaning that they're superior to the physicians that are mak- ing these decisions, but l've become convinced that it isn't good enough. What I mean by that it's not that the people aren't good enough, but the information and the lines of science they have access to for this question needs to be very integrated. In important and substantive ways and that in a sense, I guess, I'm arguing that just as my field alone would not be enough, or psychology alone would not be enough, medically trained knowledge would not be enough, right.

Dr. Hillyer: I think what you said there is definitely key, and it gives me hope seeing that they had already used, I think, five articles that you have been a part of in the current guidelines and policies and utilized one of your books. So, with this new book, "The Safe Infant Sleep: Expert Answers to Your Co-Sleeping Questions." What would be the one thing that you would want them to highlight moving forward as they create this next policy?

Dr. McKenna: It's something; actually, l've been arguing since 1996 or even before that they make a distinction from the act of bed-sharing itself and the conditions and circumstances by which it occurs. Stop focusing only on the outcome, which is, of course critical, it's the bottom line. How the outcome becomes the outcome and that there are millions, as we speak millions of mothers that are going uneducated to the very safest form of breastsleeping even because they are afraid to mention it because of pediatric pediatricians responding negatively -- Lactation support, who I admire remarkably around the world, women [are] giving generously of their time to help mothers everywhere. It's incredibly impressive Kimberly, I have been humbled by these women thousands, tens of thousands of them. Their voice has been, you know, silenced; their jobs have been threatened if they even mention the word...co-sleeping. You have people making these laws that don't know anything about the subject. They think they do. They say, "oh my gosh, four babies just died last week from cosleeping." Well, that's tragic, but how did those babies die? That's important to include in the disciplines. Then we eliminate those factors that actually explain the debt, just like we have done with crib sleeping because it isn't going away. That is what I am hoping, and other people need to be members of that, heretofore very insular group and paradigm that's actually being used.

Dr. Hillyer: Well, I want to thank you for lending your voice to this broadcast and educating our viewers a little bit more on this aspect. I really do look forward to seeing this movement not only in neonatology but through the Academy of Pediatrics with the continued work that you have been doing, and I really appreciate your time today.

Dr. McKenna: Kim, thanks so much for allowing me, giving me the privilege of speaking to your colleagues. I really am very thankful and appreciative.

Dr. Hillyer: No problem and I want to thank everyone for joining us today; and Dr. McKenna's book is "Safe Infant Sleep: Expert Answers to your Co-sleeping Questions." Thank you, from Neonatology Today.

Dr. McKenna: Thank you.

Disclosure: The authors have no disclosures.

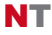




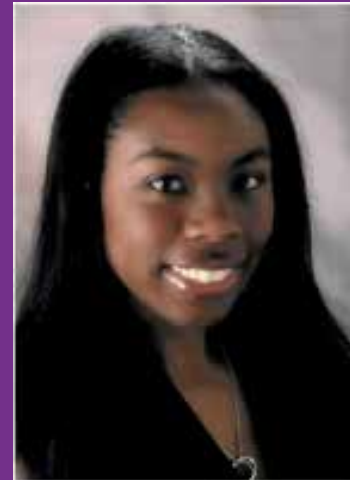

Title: NT News Anchor and Editor

Title: Neonatal Nurse Practitioner \& News Anchor, Editor for Neonatology Today

Organization: Loma Linda University Health Children's Hospital

Neonatology Today in partnership with Loma Linda University Publishing Company.

Bio: Kimberly Hillyer, RN LNC, NNP-BC DNP, completed her Master's degree specializing as a Neonatal Nurse Practitioner in 2006 and completed her Doctorate of Nursing Practice (DNP) at Loma Linda University in 2017. She became an Assistant Clinical Professor and the Neonatal Nurse Practitioner Coordinator at Loma Linda University. Her interest in the law led her to attain certification as a Legal Nurse Consultant at Kaplan University.

As a Neonatal Nurse Practitioner, she has worked for Loma Linda University Health Children's Hospital (LLUH $\mathrm{CH}$ ) for twenty years. During that time, she has mentored and precepted other Neonatal Nurse Practitioners while actively engaging in multiple hospital committees. She was also the Neonatal Nurse Practitioners Student Coordinator for LLU CH. A secret passion for informatics has led her to become an EPIC Department Deputy for the Neonatal Intensive Care at LLUH CH.

She is a reviewer for Neonatology Today and has recently joined the Editorial Board as the News Anchor.

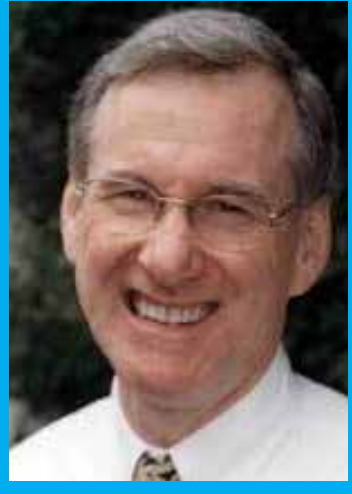

Professor James J. McKenna is recognized as the world's leading authority on mother-infant cosleeping in relationship to breastfeeding and SIDS. In recognition of his work in $\mathbf{2 0 0 9}$ he was admitted as a Fellow into the select body of the American Association for the Advancement of Science, the world's most prestigious scientific society. That same year and in recognition of his extensive work with television, radio, and print media he received from the American Anthropological Association the "2008 Anthropology In The Media Award" one of the top three awards presented to anthropologists by the association in recognition of his distinguished work in educating the public to the importance of anthropological concepts.

He received his undergraduate degree in anthropology from the University of California, Berkeley in 1970, his Master's Degree from San Diego State University in 1972, and his Ph.D. in biological anthropology from the University of Oregon, Eugene, in 1975.

After teaching anthropology at the University of California, Berkeley as a Visiting Assistant Professor for two years, he accepted a tenure track position (in anthropology) at Pomona College in Claremont, California, where he was awarded an Endowed Chair and received numerous teaching awards, and remained an active member of the faculty for twenty years. Professor McKenna was recruited by the University of Notre Dame in 1997, and since then has won every teaching prize he has been eligible for including most recently, the College of Arts and Letters' highest teaching award, the Sheedy Award, in 2008.

Initially Professor McKenna specialized in studying the social behavior of monkeys and apes but following the birth of his son in 1978 he began to apply the principles of human behavioral evolution to the understanding of human infancy. At the University of California, Irvine School of Medicine, Department of Neurology his research team pioneered the first studies of the physiology and behavior of mothers and infant sleeping together and apart, using physiological and behavioral recording devices.

Professor McKenna has published over 139 refereed scientific articles in diverse medical and anthropological journals on co-sleeping, breastfeeding, evolutionary medicine and SIDS, and both here and abroad. He also 
regularly gives lectures on over 20 specialized topics relating to cosleeping and breastfeeding especially to pediatric medical professionals and parents. Here in the United States he remains a primary spokesperson to the media on issues pertaining to infant-parental sleeping arrangements, nighttime breastfeeding and SIDS prevention.

He has also published two monographs on SIDS and infant sleep, and co-edited two books: Evolutionary Medicine (published by Oxford in 1999) and Evolutionary Medicine And Health: New Perspectives, also with Oxford University Press. His first trade book for parents was published in 2008 entitled: Sleeping With Your Baby: A Parents Guide To Co-sleeping, and was recently translated and made available in Spanish and Dutch, as well as other languages.

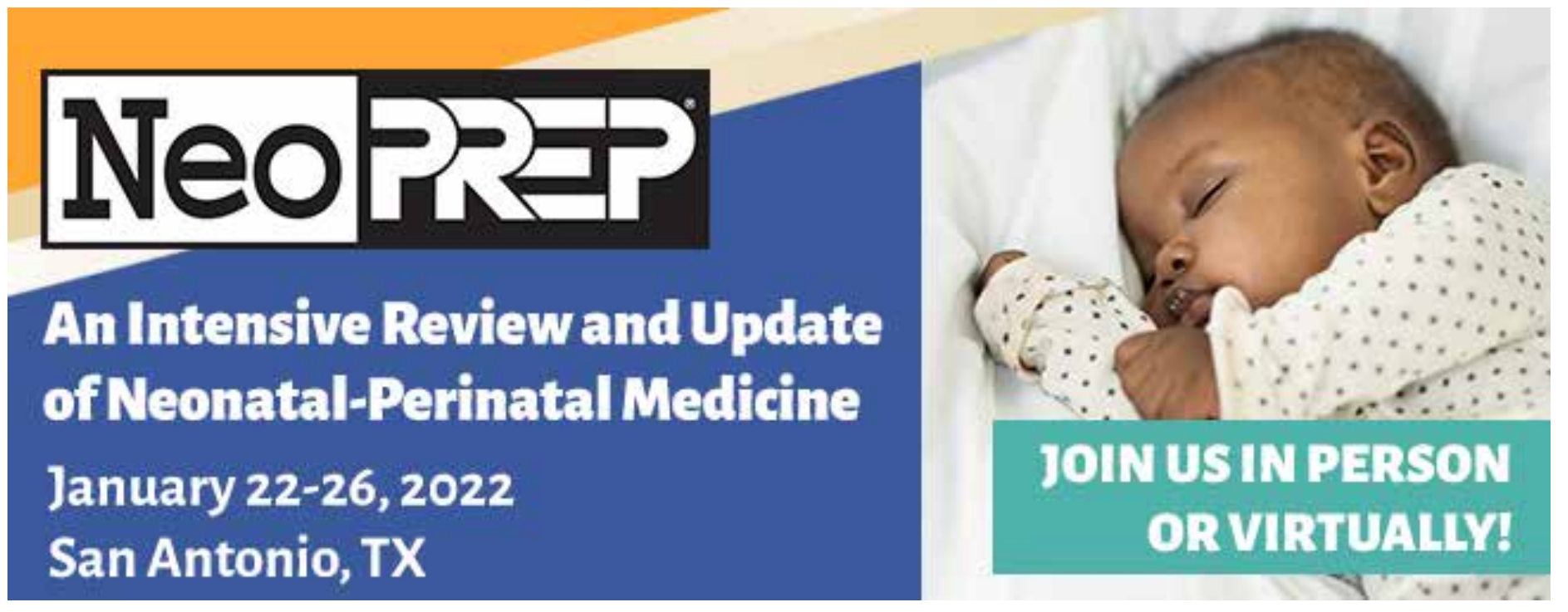

NEONATOLOGY TODAY is interested in publishing manuscripts from Neonatologists, Fellows, NNPs and those involved in caring for neonates on case studies, research results, hospital news, meeting announcements, and other pertinent topics.

Please submit your manuscript to: LomaLindaPublishingCompany@gmail.com 